\title{
A CASE OF ANOMALOUS LEFT CORONARY ARTERY
}

\author{
BY \\ HUGH FISHER AND OLIVER C. LLOYD
}

From the University of Bristol

The clinical features of a case in which the left coronary artery arises from the pulmonary artery are so characteristic, that the following example seems worth recording.

\section{Case Record}

A girl, aged 5 months, was admitted to hospital on 29/1/50 because of a failure to thrive, associated with enlargement of liver and spleen. She was breast-fed and did well for 8 weeks. As her mother's milk then failed, she was weaned to dried milk but afterwards gained weight only very slowly. There was no vomiting and the motions were normal. She appeared to be full of energy and very active.

On admission, her general condition was good; weight $5.4 \mathrm{~kg}$. (birth weight $3 \cdot 1 \mathrm{~kg}$.). Rectal temperature $99^{\circ}$. Pulse 120 , respirations 30 a minute. Retraction of the costal margin with inspiration. Trachea central. Apex beat in fifth space in anterior axillary line. Heart sounds, normal. Liver smooth and enlarged, $4 \mathrm{~cm}$. below costal margin. Spleen palpable, $1 \mathrm{~cm}$. below costal margin. Blood count: Hb. 10.7 g. per $100 \mathrm{ml}$. $(72 \%)$; R.B.C. 3.9 million per cu. mm.

Radioscopy by Dr. R. H. Owen showed the transverse diameter of the heart increased, the enlargement being mainly ventricular, with the right side more prominent than the left.

For the first two days in hospital she took her feeds fairly well though very slowly. She appeared to have colic quite frequently afterwards and vomited small amounts on four occasions. On February 1 her respiratory rate rose to 68 a minute and crepitations could be heard at the base of both lungs. Pulse and temperature were unchanged. A diagnosis of bronchopneumonia was made and she was given penicillin. She appeared to improve after five days and her respiratory rate returned to 30 a minute. She became more difficult with her feeds and on the tenth day she had a sudden collapse during a feed, with pallor, sweating, and tachypnœa. There were rhonchi and crepitations in both lungs. Her temperature rose to $103^{\circ}$, pulse to 140 and respirations to 70 a minute. The heart sounds were "tic-tac." She appeared to improve a little, but the following night collapsed again while being fed, and had severe colic, pallor, sweating, tachypnœa, this time with cyanosis, and required oxygen to revive her. From this time she collapsed after every feed, until her death in an attack on the thirteenth day.

Necropsy findings. (P.M. 2788). A slightly wasted infant $(4.6 \mathrm{~kg} ., 63 \mathrm{~cm}$. long).

The heart weighed $85 \mathrm{~g}$., which is about double the normal weight for this age. This enlargement was mainly due to left ventricular hypertrophy. The left coronary artery arose from the left posterior pulmonary sinus. The left atrium showed thickening of the endocardium but the mitral valve was natural. The left ventricle was greatly dilated and the musculature was for the most part hypertrophied, except at the apex, where it was greatly thinned and fibrotic, leading to early aneurysmal dilatation at this point (Fig. 1). The right coronary artery had its normal origin from the anterior aortic sinus. The distribution of the coronary vessels over the surface of the heart was such that the greater part of the left lateral and apical surfaces of the ventricles received venous blood from the pulmonary artery. The liver and spleen showed venous congestion from heart failure. There was also bronchopneumonia. 


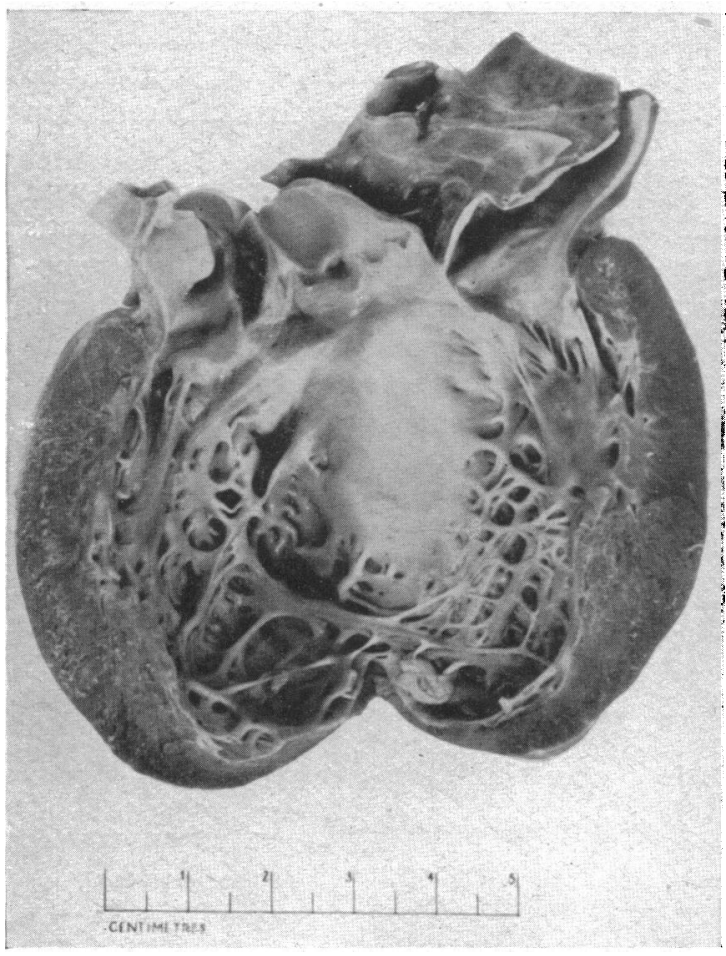

FIG. 1

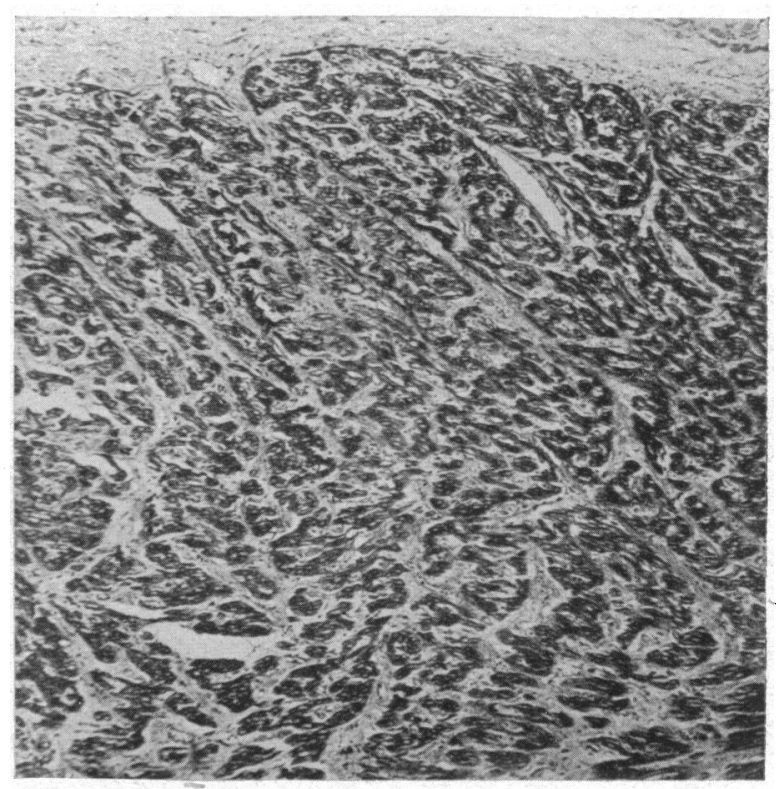

FIG. 2

FIG. 1:-Left ventricle and aortic valves opened to show dilatation and muscular hypertrophy, with fibrotic thinning at apex. The anterior cusp of the mitral valve has been cut through and the right coronary artery is seen originating normally in the anterior aortic sinus.

Fig. 2.-Apex of left ventricle (Masson's trichrome). Diffuse fibrosis. ' $\times 70$.

Histology. Left atrium: hypertrophy and fibrous thickening of endocardium. Left ventricle: great hypertrophy with a few patches of fibrosis. The tip of the left ventricle showed the greatest degree of fibrosis. The collagen was laid down next to the blood vessels, so that it surrounded each little muscle bundle. Much muscle had atrophied, but the surviving fibres were hypertrophic (Fig. 2). This appearance is quite different from an adult ischæmic fibrosis, where one sees islands of surviving muscle in a sea of fibrous tissue.

\section{Discussion}

The origin of the coronary arteries in this case is illustrated in Fig. 3. When the left but not the right coronary artery arises from the pulmonary trunk it produces a group of symptoms and signs that, as Bland et al. (1933) first pointed out, may allow a diagnosis to be made during life. The electrocardiograph is characteristic: there is inversion of the $T$ waves in all three leads, with no axis deviation and the QRS complexes may be of low amplitude. Venous blood is supplied to the myocardium of the left ventricle at a low pressure, so that the resulting ischæmia is more severe than in cases of cyanotic heart disease, when only the former factor operates. Myocardial fibrosis follows, usually without infarction, producing dilatation of the ventricle and hypertrophy of the surviving muscle. This provides an interesting illustration of the fact that hypertrophy may result from dilatation in the absence of valvular disease or hypertension. Symptoms usually appear at the age of 3 to 4 months which is about the time when, following complete closure of the ductus arteriosus, the systolic pressure of the pulmonary circulation first falls below that of the systemic. 
The condition is often fatal by the age of 6 mohths. Gasul and Loeffler (1949) list 26 cases that have now been reported; all except 5 died in infancy, but the remainder were symptom free and reached adult life. Post mortem, the latter were found to have developed a collateral circulation between the two coronary arteries.

Clinical picture. The most significant symptom is what appears to be severe colic associated with pallor, sweating, and tachypnœa during or after a feed. It is probably equivalent to angina pectoris in an infant. This results in malnutrition. Later, cardiac failure develops and respiratory symptoms become prominent. Many of these cases are mistakenly thought to have bronchopneumonia. The heart progressively increases in size. Hepato-splenomegaly as a result of chronic venous congestion is frequently present. In this case it was the reason for the child's admission for investigation. Cyanosis is only a late sign. Edema of the extremities may also occur. No murmurs are to be heard on auscultation.


FIG. 3.-Diagram illustrating embryology of anomalous origin of left coronary artery. The diagram on the left shows the origin of the coronary arteries from the truncus arteriosus. The two diagrams on the right show how the development of the spiral septum has produced the aorta and pulmonary artery. The dotted lines show the normal origin of the left coronary artery from the posterior part of the left lateral bulbar cushion.

The diagnosis is confirmed by fluoroscopy and electrocardiography. An X-ray shows the heart to be greatly enlarged, the left ventricle being most prominent. Taussig (1947)-mentions that there may be a difference in the force of contraction of the two ventricles. In the left anterior oblique position, the right ventricle anteriorly may be seen to pulsate normally, while the left ventricle posteriorly shows only weak pulsations.

\section{Summary}

A case is described of a child dying of cardiac failure due to the anomalous origin of the left coronary artery from the pulmonary artery. The necropsy findings are described.

Our thanks are due to Dr. B. D. Corner for permission to publish this case, to Dr. R. H. Owen for the radiological findings and to Mr. G. H. Rogers for the photographs.

\section{REFERENCES}

Bland, E. F., White, P. D., and Garland, J. (1933). Amer. Heart J., 8, 787.

Gasul, B. M., and Loeffler, E. (1949). Padiatrics, 4, 498.

Taussig, H. B. (1947). Congenital Malformations of the Heart. 1st ed., New York, p. 321. 